\title{
HAS FINANCIAL MARKET INTEGRATION INCREASED DURING THE NINETIES?
}

Juan Ayuso and Roberto Blanco

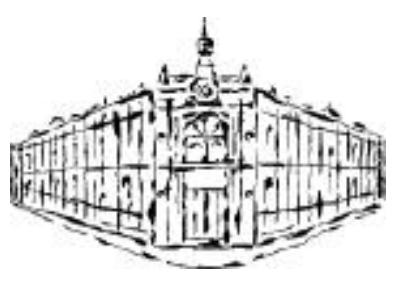

Banco de España - Servicio de Estudios

Documento de Trabajo n. ${ }^{\circ} 9923$ 


\title{
Banco de España \\ Research Department
}

\section{HAS FINANCIAL MARKET INTEGRATION INCREASED}

\section{DURING THE NINETIES?*}

\author{
Juan Ayuso \\ Roberto Blanco
}

December 1999

\begin{abstract}
This paper analyses whether there has been an increase in the degree of financial market integration during the nineties. To do this, we focus on stock markets and compute, first, a number of standard measures of co-movements that sometimes are interpreted as measures of financial integration. In our view, they only measure financial market linkages. In any case, this analysis allows us to make a more formal assessment of the actual increase in linkages and, at the same time, highlights the shortcomings of these measures of financial market integration. In the second part of the paper we compute two alternative measures of market integration based on a refinement of the approach suggested by Chen and Knez (1995). The main advantage of this approach is that it relies on the condition of absence of arbitrage opportunities -which is directly related to the idea that more integration means less barriers to trade across markets- and does not depend on any particular asset pricing model. The evidence found suggests that during the nineties there has been an increase of the degree of market integration between stock markets.
\end{abstract}

\footnotetext{
* Paper prepared for the Autumn Central Bank Economist's Meeting held at the BIS on the 25 and 26 October 1999. We wish to thank Francisco Alonso for outstanding research assistance, and Enrique Alberola, José Luis Escrivá, Jorge Martínez and participants in the BIS' Meeting and in the internal seminar at the Banco de España for very helpful comments and suggestions.
} 


\section{INTRODUCTION}

Financial crises are not a new phenomenon. What seems to be new, however, is their increasing ability to become world-wide. During the last few decades the widespread liberalisation of capital movements has fostered fierce competition among financial services providers while a parallel process of technological innovation has supplied the means to move huge capital amounts quickly and safely across borders. In this new framework, financial markets quite often provide examples of the well-known "butterfly effect", the easing of the FED monetary policy in response to the collapse of LTCM being, perhaps, one of the most recent. Furthermore, it is hardly debatable that the weight of foreign assets in agents' portfolios has markedly increased during the last few years -Chart 1 shows, for example, the rising path of the direct and portfolio investment abroad of a number of selected countries. In these circumstances, it is argued that the international integration among domestic financial markets has grown to such a point as to render them too vulnerable to relatively unimportant news. Nevertheless, a more thorough analysis seems to be needed before reaching such a conclusion.

Indeed, the evidence above only reveals that, at least to some extent, financial market linkages have increased. Yet closer linkages do not necessarily imply higher financial market integration -i.e. an additional removal of barriers of any kind to cross-border financial transactions. Thus, it could be argued that not only financial markets but also economies, as a whole, have reached a higher level of internationalisation. Cross-border commercial linkages have increased as well. Moreover, it should be borne in mind that the same technological innovations that have paved the way for cross-border financial transactions have also increased the world-wide diffusion of information in real time. Accordingly, it could be the case that the main driving force behind the apparent increase in financial market linkages is the globalisation of the news that affects financial prices instead of a higher degree of market integration.

In our view, it is important to determine whether there has been a genuine increase in financial market integration. It is worth noting that the assessment of a hypothetical increase in financial market linkages will depend on the causes of the increase. In terms of welfare, for example, it should be clear that whereas a removal of barriers implies an increase in diversification opportunities -thus reducing the levels of risk that agents have to accept to obtain a given return- a greater globalisation of the relevant information set would mean exactly the opposite. Similarly, the implications of each scenario regarding the need for a global supervisor would be different if information, instead of markets, is more global. 
The main goal of this paper is to investigate whether there has been a genuine increase in the degree of financial market integration during the nineties. To do this, we focus on stock markets and compute, first, a number of standard measures of financial market integration that, in our view, only measure financial market linkages. This will allow us to make a more formal assessment of the actual increase in financial market linkages and, at the same time, the shortcomings of these measures as indicators of financial market integration will become clearer. Second, we analyse whether there has been any notable advance in the degree of "pure" financial market integration by computing two alternative measures of market integration based on a refinement of the approach suggested in Chen and Knez (1995).

The paper is organised as follows. After this introduction, Section 2 computes standard measures of market linkages that reveal a higher degree of linkage but are unable to show whether this is due to higher market integration or to other factors. Section 3 addresses into this question and computes direct measures of the changes in market integration during the nineties that show an increasing degree of market integration over this decade. Finally, Section 4 summarises the main results and points out some of their potential policy implications.

\section{STANDARD MEASURES OF LINKAGES BETWEEN INTERNATIONAL STOCK PRICES}

Perhaps the simplest approach in the literature to analyse the degree of market integration is that based on the computation of the correlation between returns on those markets that are thought to be more integrated than previously ${ }^{1}$. This approach is based on rather simple intuition: the more integrated markets are, the higher the co-movement between their prices. In this respect, Table 1 shows the correlation between weekly returns on seven selected stock exchanges -New York, London, Paris, Madrid, Frankfurt, Milan and Tokyo 2 during the 1990-1994 and the 1995-1999 periods. In 15 out of the 21 possible combinations, correlation has increased in the second half of the nineties, with the Japanese stock exchange accounting for the remaining 6 cases. On average, the correlation between the returns on these stock exchanges increased from .42 during the period 1990-1994 to .54 during 1995-1999.

\footnotetext{
${ }^{1}$ See, for example, Taylor and Tonks (1989) or Le (1991).

2 Returns have been obtained as the first difference of the logarithm of a representative index for each stock exchange: S\&P500, FTSE ALL-S, CAC40, IGBM, DAX30, MIB and NIKKEI225. See Annex 1 for details about the data used.
} 
Although this evidence can be considered as supporting the view of a higher degree of financial market linkages, it is well known that higher correlation is neither a necessary nor a sufficient condition for greater market integration ${ }^{3}$. If markets are completely integrated and, therefore, there are no arbitrage opportunities, returns on different assets can be divided into a common component and an idiosyncratic one. The latter, however, may be sufficiently important as to render ex-post correlation rather low.

To illustrate this point, the bottom panel of Table 1 replicates the same exercise for seven selected sub-indexes of the New York Stock Exchange. Although there are no reasons to think that this stock exchange was less self-integrated during the first half of the nineties, 13 out of 21 correlations increased in 1995-1999. Moreover, the average correlation between groups of shares within the New York Stock Exchange in 1995-1999 is .47, lower than the average correlation between the selected national stock exchanges during the same period. Given that it is not reasonable to think that the degree of market integration is higher across stock exchanges than within any of them we have to conclude that this approach is flawed.

An alternative approach builds on the previous one and is aimed at measuring to what extent the returns on other markets can help to explain the returns on one particular market. Table 2 shows the main results of this approach, which consists here of a comparison between the (sum of the squared) residuals of a simple univariate autoregressive model for each return and the (sum of the squared) residuals of a VAR model for the seven returns considered. First of all, it has to be noted that the seven markets considered do not share common trading hours and consequently implications can not be drawn from comparisons between countries within the same period ${ }^{4}$. Nevertheless, we are not interested in the comparison between countries within the same period but in the comparison of different periods for the same country. Yet there is no reason to think that the implications of the different trading hours -whatever they might be- have changed in the second half of the nineties.

According to Table 2, during the first half of the nineties the sum of the squared residuals is reduced, on average, by $6.98 \%$, when other-market returns are taken into account to explain the behaviour of stock returns. During the second half of the decade, the reduction amounts to $14.04 \%$, thus revealing a higher average degree of linkage between the markets considered. This increased linkage is moreover uniform across the seven countries and could even be underestimated in Table 2 given that the VAR approach adds only 6

\footnotetext{
${ }^{3}$ See, for example, Adler and Dumas (1983).

${ }^{4}$ For example, the relatively low improvement ratio for the New York stock exchange could be due to the fact that this is the stock exchange that closes the latest each day, thus being open to news that arrives when other stock exchanges are closed.
} 
parameters to each univariate model in the $1995-1999$ period whereas 12 parameters are added in the $1990-1994$ period $^{5}$

In order to evaluate the magnitude of the recorded increases in linkages, the bottom panel of Table 2 replicates the exercise for the same seven sub-indexes of the New York Stock Exchange as in Table 1, thus offering a useful yardstick. During the second half of the decade there is also an increase in the explanatory power of the other-market returns. Nevertheless this increase has three interesting features. First, it is clearly lower (from $1.27 \%$ to $1.76 \%$ ) than that in the upper panel. Second, it is not uniform across sectors (only 4 out of seven show an improvement). And third, the levels of the reduction in the sum of squared residuals in each period are somewhat lower than those corresponding to the seven-country case (1.27\% and $1.76 \%$ versus $6.98 \%$ and $14.04 \%)$. Accordingly, it could be concluded that the increase in the linkages between the returns on the stock exchanges chosen is quite genuine.

To further investigate the nature of the recorded increases in linkages, another sort of robustness test is offered in Table 3. This table replicates the same exercise as Table 2 but having eliminated the biggest outliers from the series. The idea behind this exercise is to test to what extent the previous results are due to the presence of a few big outliers that are common to all series -as, for example, when a sudden crisis emerges. Thus, days have been selected in which at least one of the seven series showed returns two standard deviations away from its average. For each of these dates (160 in total, i.e. a $6.53 \%$ of the sample) a dummy variable taking the value 1 on that day and 0 otherwise has been built. Finally, all these dummy variables have been used as a common set of interventions. That is, each stock exchange return has been regressed on all dummy variables and the residuals have been taken as the new returns to perform the same exercise as in Table 2.

When outliers are removed, the sum of squared residuals is, on average, reduced even more sherply in 1995-1999 than in 1990-1994 (5.71\% versus 5.37\%). Regarding individual country data, however, only in three out of the seven possible cases is the reduction higher in the second half of the nineties. Nevertheless, this comparison is to some extent flawed, because as commented above, in the first period the univariate models are enlarged with six more parameters than in the second period when the VAR model is estimated. This biases the results against the information content of other-market returns during 1995-1999. To circumvent this problem, we have over-parameterised the second period by including an additional lag in the VAR model. After this modification, the reduction in the sum of squared residuals is, on average, higher in 1995-1999 (6.65\% versus 5.37\%) and affects 5 out of 7

\footnotetext{
5 In 1990-1994 the VAR model includes 2 lags, whereas in 1995-1999 a single lag is sufficient to eliminate any residual autocorrelation. Accordingly, when compared to the univariate model, the VAR adds 12 more parameters ( 2 lags $\times 6$ countries) during the first period and only 6 ( 1 lag $\times 6$ countries) during the second one.
} 
countries. When compared to Table 2, results in Table 3 are certainly less clear-cut but still point towards an increase in the linkages between stock prices.

Nevertheless, it is not possible in this case either to draw any firm conclusion from the apparent higher financial market linkages on the changes in the degree of financial market integration. As a matter of fact, there are cases in which a lower predictive power of othermarket returns might be reflecting a higher degree of market integration. Thus, for example, it could be argued that if information flows efficiently, any relevant news -i.e. disregarding idiosyncratic shocks- would be immediately absorbed by all prices quoted on any market. Accordingly, in a model like the VAR estimated above, other-market (lagged) returns should not contain any relevant information provided that the own-market (lagged) returns are taken into account. From this standpoint, the results in Tables 2 and 3 might even be seen as pointing towards less efficiency in the transmission of information -i.e. greater barriers to financial trade and therefore less integration.

Tables 1 to 3 address the issue of market linkages by focusing on stock return levels. Nevertheless, there are also other statistical moments that could be analysed to draw further relevant information on the relationships between financial markets. In particular, it is also of interest to analyse whether there is greater linkage between stock price volatilities. In Engle, Ito and Lin (1988), volatility linkages are explored to draw conclusions on market efficiency from the way information arrives in financial markets and is transmitted between them.

As it is well known, the question of how volatility should be measured has received an almost unanimous answer in the literature: by estimating the conditional variance of the series considered. There are, however, several models available to make such an estimate $^{6}$. In this paper, we estimate the model proposed in Glosten, Jagannathan and Runkle (GJR) (1989). This model consists of a small variation to the GARCH model proposed by Bollerslev (1986). Nevertheless, this variation is highly significant since it allows the new model to capture an important feature of stock returns: the leverage or asymmetric effect firstly noted by Black (1976). The importance of this innovation is highlighted in Engle and $\mathrm{Ng}$ (1993), who perform an interesting horse race between several conditional variance models to explain the behaviour of the conditional variance of Japanese stock returns and conclude that "the best model is the one proposed by Glosten, Jagannathan and Runkle".

In this paper, we first estimate a GJR model for each of the residual series of the VAR model. These models are next enlarged to include the lagged (squared) residuals corresponding to the remaining markets as new explanatory variables. In particular, as we

${ }^{6}$ See, for example, Engle and $\mathrm{Ng}$ (1993) for an extensive comparison among alternative methods. 
are interested in testing whether the role of the other-market residuals has increased, we include as new regressors each other-market (squared) residual and the product of each other-market (squared) residual times a step dummy variable which takes the value 1 during the period 1995-1999 and 0, otherwise. Consequently, a positive and significant value of the coefficient of the latter would imply an increasing role of the corresponding other-market volatility to explain the volatility of the own market.

Formally,

[1] $h_{i, t}=a_{0}+\sum_{k=1}^{q 1} a_{k} e_{i, t-k}^{2}+\sum_{k=1}^{q 1} g_{k} e_{i, t-k}^{2} S_{i, t-k}^{-}+\sum_{k=1}^{q 2} b_{k} h_{i, t-k}+\sum_{j \neq i}\left(\sum_{k=1}^{q 1} d_{j, k} e_{j, t-k}^{2}+\sum_{k=1}^{q 1} d d_{j, k} e_{j, t-k}^{2} S S_{t-k}\right)$

where,

$e_{i, t}=r_{i}-E_{t-1}\left(r_{i, t}\right) ; e_{i, t} \mid \Omega_{t-1} \sim N\left(0, h_{i, t}\right)$ and $E_{t-1}\left(r_{i, t}\right)$-i.e. the conditional expectation on $r_{i, t}$ - is computed from the VAR model.

$\mathrm{i}, \mathrm{j}=\mathrm{JAP}, \mathrm{UK}, \mathrm{GER}, \mathrm{FRA}, \mathrm{ITA}, \mathrm{SP}, \mathrm{USA}$.

$S_{i, t}^{-}=1$ if $e_{i, t}=1 \leq 0$ and 0 , otherwise.

$S S_{t}=1$ from 1995 to 1999 and 0, otherwise.

It is worth noting that the VAR model includes the levels of the other-market returns as explanatory variables for each own-market return. Accordingly, the possibility can be ruled out that other-market squared residuals appear as significant in the conditional variance equation only as a consequence of (level) residuals being an omitted variable in the conditional mean equation.

Table 4 shows the main results of the exercise. First of all, it has to be noted that the GJR models fit reasonably well, as shown by the standard goodness-of-fit tests reported in the table $(\mathrm{CH} 1, \mathrm{CH} 5, \mathrm{~T} 1, \mathrm{~T} 2$ and $\mathrm{T} 3)$. The leverage effect -that is, the coefficient $\mathrm{g}_{1}-$ is also important in all but one country. Regarding volatility linkages, however, the picture emerging from Table 4 is rather less clear-cut than that regarding the linkages between return levels.

In general, the estimated coefficients suggest that, compared to the weight of the innovations in the own market, other-market variability does not play an important role in explaining each own-market conditional variance. When the first and the second half of the nineties are compared, in three cases (Japan, France and USA) other-markets squared residuals account for a higher part of the own-market volatility during the 1995-1999 period. In Italy, there are no significant changes during the nineties. In another case (Germany) the role of other-market residuals is lower during the second half of the decade. And finally, 
there are two cases (UK and Spain) in which there seems to have been a simple change of protagonist. Thus, for example, UK volatility was more sensitive to the variability in France during the first half of the decade whereas during the second half Germany was the main source of additional volatility.

Thus, once the effects of other-market return levels are taken into account to explain the level of returns in each market, the evidence in Table 4 does not offer clear support to the view of an increasing volatility linkage during the nineties. Nevertheless, it has to be borne in mind that, as commented above, a more prominent role of innovations in a market to explain the volatility of other-market returns might be interpreted as a sign of informational inefficiency. Accordingly, the evidence in Table 4 could also be seen, at least to some extent, as a sign of a high degree of market integration.

All in all, the results in this section seem to give mild support to the existence of an increase in stock market linkages, which is clearer in the case of levels than in that of volatility. Nevertheless, it remains to be seen whether these greater linkages are the consequence of a genuine higher degree of market integration or merely reflect the greater globalisation of the main sources of the news which drives stock prices. Addressing this question is the main goal of the rest of this paper.

\section{MEASURING FINANCIAL MARKET INTEGRATION}

\subsection{Conceptual framework}

Perfect cross-market integration is generally understood as a situation in which there is no barrier of any kind to cross-border financial transactions, such as tariffs, taxes, restrictions on the trading of foreign assets, information costs or any other cost that makes it more difficult to trade across countries than within them. With perfect cross-market integration there are no cross-market arbitrage opportunities and the law of one price -i.e. portfolios with the same payoffs should have the same price in different markets- holds. It is worth noting, however, that, as suggested above, the law of one price or the absence of arbitrage opportunities can not be assessed from the analysis of the co-movement of the levels of financial asset prices or of their volatilities.

Although this point can be made without reference to any specific asset pricing model, it is easier to illustrate it if a particular model is considered. Thus, for the sake of simplicity, let us assume that assets are priced according to the well-know APT model. Under this model 
each (ex-post) asset price is equal to the sum of the products of a number of random factors (the sources of risk) multiplied by their coefficients (generally called risk prices) plus the realisation of an idiosyncratic shock. If markets are perfectly integrated these random factors have to be equally priced in each market. Accordingly, an increase in the degree of integration between markets that were previously segmented should increase the comovements of their prices due to the reduction in the differences between the prices of the common risk factors. Nevertheless, increases in the co-movements may also be the result of a greater intersection of the sets of risk factors affecting prices in both markets -possibly as a result of a greater globalisation of news- while differences in the risk prices remain. Similarly, a reduction of the weight of the idiosyncratic shocks would also result in a higher (ex-post) co-movement independently of the degree of market integration.

Against this background, Chen and Knez (1995) developed a measurement theory of market integration that relies directly on the concept of the law of one price and the condition of absence of arbitrage opportunities and does not depend on any particular asset pricing model ${ }^{7}$. Following the seminal work of Hansen and Jagannathan $(1991,1997)$ the measures they proposed exploit certain properties of the stochastic discount factors. The latter are random variables $\mathrm{d}$, which are implicitly defined in the following unconditional moment restriction:

$$
E\left(p_{i}\right)=E\left(x_{i} d\right) \quad \forall i \in N
$$

where $E($.$) is the expectation operator, p_{i}$ is the price of asset $i, x_{i}$ is the future payoff of that asset $^{8}$, and $\mathrm{N}$ is the number of assets traded in the market studied. Expression [2] is derived by applying the law of iterated expectations to the equilibrium condition of a generic asset pricing model: prices of a future payoff on any traded security have to be equal to the expected product of the payoff and the intertemporal marginal rates of substitution ${ }^{9}$. All

\footnotetext{
7 In the literature other approaches that test for integration based on the notion of absence of arbitrage have been developed (for instance, Adler and Dumas use an international CAPM). However, as pointed out by Chen and Knez (1995), the main shortcoming of these approaches is that any test of market integration is, at the same time, a test of the particular asset pricing model used.

8 This model assumes the existence of only two periods. In the first one, assets are traded; in the second, investors obtain the payoffs.

${ }^{9}$ This is the so-called Euler equation, which is common in all existing asset pricing models. Particular models differ on the specification of consumers' preferences and, therefore, of the marginal rate of substitution.
} 
random variables $d$ satisfying equation [2] make up the family of admissible stochastic discount factors. It is found that under certain conditions the pricing structure of a market can be completely summarised by these discount factors.

Chen and Knez (1995) showed that the law of one price holds across the two markets if and only if the intersection between their sets of admissible stochastic discount factors is not empty $^{10}$. Based on this result, they proposed to measure the degree of market integration as the (square of the) minimum square distance between the sets of the admissible stochastic discount factors in the two markets ${ }^{11}$. Note that this measure is zero if and only if the two markets are perfectly integrated. A strictly positive value for this measure indicates the degree of segmentation: the lower the measure, the more closely integrated the two markets. Applying a result taken from Hansen and Jagannathan $(1997)^{12}$, this measure can be interpreted as the maximum (squared) difference between the prices assigned by two markets to any unit-norm common payoff ${ }^{13}$. Thus, this measure reflects the magnitude of pricing discrepancy between the two markets and, to some extent, indicates the minimum costs necessary to prevent investors from taking advantage of the pricing discrepancy.

In order to implement the measure empirically, Chen and Knez (1995) proposed to use data on prices and payoffs for a sample of securities in two markets and to approximate population moments with sample moments. Formally, the set of admissible discount factors $d$ in market $j-D_{j}$ - is made up of any vectors of dimension $T$-the number of time series observations- that satisfy the following $\mathrm{N}_{\mathrm{j}}$ restrictions ${ }^{14}$ :

[3]

$$
O P_{j}=d X_{j}
$$

\footnotetext{
10 They also proved that cross-market arbitrage opportunities do not exist if and only if the intersection between the sets of nonnegative admissible stochastic discount factor is not empty.

11 They called this the weak integration measure. They also proposed another measure --the strong integration measurewhich computes the same distance when only the nonnegative elements of those sets are taken into account

12 Hansen and Jagannathan (1997) showed that the least square distance between a random variable and the set of admissible stochastic discount factors of one particular market gives the maximum pricing error in using that random variable to price any unit-norm payoffs traded on that market.

13 The strong integration measure can be interpreted as the mini-max bound on the (squared) pricing differences when using the nonnegative stochastic discount factors of the two markets to price any conceivable unit norm payoff.

14 These restrictions are the sample counterparts of the population restrictions of expression [2].
} 
where $\mathrm{O}$ is a vector of ones with dimension $T, P_{j}$ is the matrix of the prices of the $N_{j}$ securities traded in market $j$ and $X_{j}$ is the matrix of the payoffs of the same securities.

It is worth noting that the value of the estimated integration measure depends on the combination of the values chosen for $T$ and $N_{A}+N_{B}$. In particular, it is straightforward to show that if $T$ is higher than $N_{A}+N_{B}$ and the rank of $X_{A+B}$ is $N_{A}+N_{B} 15_{-i}$.e. two portfolios with equal payoffs, one from each market, cannot be constructed- the intersection between $D_{A}$ and $D_{B}$ will be non-empty because the system resulting from jointly considering [3] in both markets does have a solution. In this case the estimated integration measure will always be equal to zero. Note that in this situation cross-market arbitrage is not possible because we cannot form two portfolios with the same payoffs in both markets, not because both portfolios are equally priced. Thus, under these circumstances, the integration measure will be uninformative ${ }^{16}$.

Two lessons can be drawn from the previous comments. Firstly, when implementing the integration measure, attention has to be paid to the election of $T, N_{A}$, and $N_{B}$. Secondly, the absolute value of the integration measure is difficult to interpret. In other words, it would be preferable to use it in relative terms -i.e. comparing pairs of markets or periods.

In this paper, we apply the methodology described above to assess how market integration has changed during the nineties. More specifically, we compute two different integration measures -both based on this theory- for pairs of markets in the period 1990-94 and compare them with those obtained for the period 1995-99. To undertake this exercise we use daily data on prices and payoffs ${ }^{17}$ denominated in US dollars for a sample of securities traded in three out of the seven stock exchanges considered in Section 2 -New York, Frankfurt and Madrid.

Unfortunately, in our data set the aggregate number of securities in any pair of markets is much lower than the number of time series observations in each of the periods studied. In

\footnotetext{
15 In empirical applications this tends to occur in (almost) all cases. At least this is what we obtain with our data set.

16 Chen and Knez (1995) estimated the degree of integration between the NASDAQ and the NYSE computing their integration measures, but they did not take into account this observation. The estimated figures they got are very low but nonzero probably as a result of the algorithm they applied, which can not produce a zero value as it stops when convergence is supposed to be reached.

17 The payoffs are computed taking into account splits, dividends and capital increases in addition to capital gains -i.e. price changes-. See Annex 1 for more details about the data used.
} 
order to avoid the uninformative solution mentioned above, we have followed two alternative approaches. Under the first one, we compute the (square root of the) integration measure proposed by Chen and Knez (1995) using only monthly data, which left us with only 53 observations in each period $^{18}$. This figure is lower than the total available number of assets in the American exchange, which overcomes the trivial solution. The problem with this approach is, firstly, that we lose some of the available information. Also, it should be recognised that this is a "tricky" approach since we force data to guarantee the existence of two portfolios -one from each market - with common payoffs. In fact, both portfolios might have different payoffs if we considered more periods.

The second approach relies on weekly data, which give us with 230 observations in each period. In this case, the problem of getting an uninformative zero value is overcome by computing mean distances between the sets of admissible discount factors instead of minimum distances. Of course, the mean distance between two sets could be strictly positive even if they do intersect ${ }^{19}$. Note that this measure has a different pricing error interpretation as it computes the mean -instead of the minimum- of the maximum absolute pricing errors when using the pricing rules implied by one market to price any unit-norm payoffs marketed on the other market ${ }^{20}$. Thus, this measure could be interpreted as the expected maximum pricing discrepancy between two markets.

Alternatively, the latter measure can be interpreted in terms of the expected minimum distance between the sets of discount factors in markets $A$ and $B\left(D_{A}\right.$ and $\left.D_{B}\right)$ when expanding these markets to include all assets traded. To see this, note first that the higher the number of assets the more reduced the size of the sets $D_{A}$ and $D_{B}$. Nevertheless, given that information is always limited these sets will tend to be too large and we will find a nonempty intersection -and, therefore, a zero minimum distance. Yet in this case, we can still distinguish between cases like those in Chart 2. In general, as the information set expands and sets $D_{A}$ and $D_{B}$ reduce, the minimum distance will tend to increase. If it becomes finally non-negative, it can be expected it to be higher in the left-hand situation. That is, the higher the mean distance between $D_{A}$ and $D_{B}$, the higher the expected minimum distance,

\footnotetext{
18 The number of observations in the first period (1990-94) is higher than 53 , but we have reduced the size to 53 in order to make the comparison between the periods fairer, given that, as we have shown, the sample size could affect the results.

${ }^{19}$ To be more precise, as will be clear later, we introduce some restrictions that affect the value of the discount factors in order to simplify computation and to guarantee the existence of the mean.
} 
provided the information set is large enough. Or put in a different way, the lower the mean distance, the higher the probability of having a non-empty intersection when the information set is ample enough.

The procedure we have followed to implement the two integration measures introduced in the previous paragraphs has two important features. Firstly, for each of the three markets studied we form a number of sub-markets by taking different samples of assets, each one having its associated set of admissible discount factors. This allows us to have -in each period- a set of integration measures, instead of point estimates, which varies according to the particular stocks included in each sub-market. Secondly, we not only estimate the integration measures between different markets, but we also estimate them within the same market ${ }^{21}$ - the benchmark market. This allows us to have values of the integration measure for a market which is thought to be self-integrated. By construction these figures will generally be strictly positive in spite of the fact that the market is perfectly self-integrated. So, we can have a set of values for the measures which could be used as reference values for perfectly integrated markets. Thus, the relative measures of integration -defined as the difference between the absolute integration measure between two different markets and that within the benchmark market- will be easier to interpret as integration measures -i.e. a significant positive value for this relative measure will suggest that markets are not perfectly integrated.

More specifically, the procedure we have followed involves - in both approaches and in each period- the following five steps:

i) One market is taken as a benchmark.

ii) A random group of $\mathrm{N}_{\mathrm{A}}$ securities is selected from among the assets available in the benchmark market. In what follows, this group of assets will be referred to as submarket $A$ and $D_{A}$ will stand for the set of discount factors that price assets in that sub-market.

\footnotetext{
20 This interpretation follows after applying the result of Hansen and Jagannathan (1997). See footnote 10.

${ }^{21}$ In other words, in this case sub-markets $A$ and $B$ are made up of stocks belonging to the same market.
} 
iii) 100 random combinations of groups of $N_{B}$ securities are selected in each of the three markets studied. In what follows, any of these groups of assets will be referred to as sub-market $B$, and $D_{B}$ will stand for the set of discount factors that price assets in those sub-markets. So, we have 300 sub-markets $B-100$ sub-markets for each of the three markets. For the benchmark market, stocks in sub-markets B are restricted to being different to those selected in step ii).

iv) Distances 22 between the fixed set $D_{A}$ and the sets $D_{B}$ are computed. So, we get 100 distances for each of the three pairs of markets. These 100 distances are then averaged for each pair of markets. So, we finally have 3 average distances.

v) Steps ii) to iv) are repeated 100 times.

The distances computed in step iv) are estimated using two different algorithms -one for the first approach and another for the second one-, which are described next. The integration measure of the first approach -i.e. the minimum distance between sub-markets A and B- is estimated following the algorithm proposed by Chen and Knez (1995). The logic behind it is depicted in Chart 3. This algorithm involves two iterative steps. In the first step, the least square projection of a selected point in $D_{B}$ onto the set $D_{A}$ is computed. The square distance between those points in sets $D_{B}$ and $D_{A}$ is also recorded. In the second step, the least square projection of the point found in $D_{A}$ onto the set $D_{B}$ and the square distance between both points are computed. These iterative steps are repeated back and forth until the distance converges. As the first point in $D_{B}$ in the iteration process we take the least square projection of a vector of ones onto the set $D_{B}$.

The algorithm used to estimate the second integration measure -i.e. mean distance between sub-markets $A$ and $B$ - computes the least square distance between random points in $D_{B}$ and the set $D_{A}$. This estimation is repeated for different points in $D_{B}$ and the mean of the found distances is computed until convergence is reached. The points in $D_{B}$ are taken as the least square projection of a vector whose components are randomly drawn from a

\footnotetext{
22 Under the first approach the minimum distances are computed, and under the second approach mean distances are computed.
} 
uniform distribution defined in the interval $(0.5-1.5)^{23}$. This procedure guarantees the existence of a finite mean and simplifies the computation.

The iteration process in both algorithms stops once the sum of absolute changes in the estimated distance measure for the last five iterations is less than 0.05 basis points 24 . Least square distances and least square projections are estimated using the following expressions $^{25}$ :

[4] $\quad \delta_{j}=\left[\left(\frac{1}{T}\left(d X_{j}-O P_{j}\right)\right)\left(\frac{1}{T}\left(X_{j}{ }^{\prime} X_{j}\right)\right)^{-1}\left(\frac{1}{T}\left(d X_{j}-O P_{j}\right)\right)^{\prime}\right]^{1 / 2}$

[5] $\quad d_{j}^{\prime}=d^{\prime}-X_{j}\left(\frac{1}{T}\left(X_{j}^{\prime} X_{j}\right)\right)^{-1}\left(\frac{1}{T}\left(d X_{j}-O P_{j}\right)\right)^{\prime}$

where $\delta_{j}$ is the least square distance between a vector $d$ and the set $D_{j}$, and $d_{j}$ is the least square projection of one vector $d$ onto the set $D_{j}$.

\subsection{Results}

Table 5 shows the main results under the first approach -minimum distances between pairs of sets of discount factors- when the American market is used as the benchmark ${ }^{26}$ and the number of assets in sub-markets $A$ and $B$ are, respectively, 44 and 10. In these conditions, the number of time series observations -53 - is lower than the total number of assets in both sub-markets, but higher than the number of assets considered in each sub-market. Thus, we force an empty intersection between sets $D_{A}$ and $D_{B}$ provided the combined payoffs matrix has a rank of 54 . More specifically, the table shows some descriptive statistics of the 100 averages of the minimum distances between the sets of discount factors of submarkets A and B for three different pairs of markets for the 1990-95 and 1995-1999 periods.

\footnotetext{
${ }^{23}$ As a consequence, we would expect the elements of the points selected in $D_{B}$ not to be too far away from this interval.

24 This stopping rule is similar to that suggested in Chen and Knez (1995).

25 These expressions are the sample counterparts of those found by Hansen and Jagannathan (1997), which are derived after solving the optimisation problem involved.

${ }^{26}$ Due to the small number of available assets in the data set corresponding to the other two markets we could not take them as benchmark markets.
} 
Two important features emerge from Table 5. First, irrespective of the period considered, the mean of the minimum distance is lower for the pair USA-USA than for any other pair. This is a reasonable result that suggests a higher degree of market integration within the American market than between this market and either of the other two. Second, the mean of the minimum distance between every pair of markets is lower in 1995-99 than in 1990-95, suggesting an increase in the degree of integration in the second half of the decade. However, the same trend, although to a lesser extent, could be observed regarding the integration within the American market. This development may be explained by sample errors, which seem to be relatively important as suggested by the values of standard deviations.

As commented in Section 3.1, relative instead of absolute distances are probably to offer a clearer picture of the developments in the degree of market integration during the nineties. These measures are defined, for every replication, as the difference between the distance between pairs of sets associated with stocks traded in different markets and the distance computed with pairs of sets that price stocks in the benchmark market. Table 6 reports the main results of this exercise and Chart 4 plots the corresponding histograms. According to Table 6 , the mean minimum relative distance between markets has decreased during the second half of the decade. Chart 4 shows moreover, that not only has the average decreased, but the empirical distributions of the relative distances have shifted to the left in the second period. All this suggests an increase in the degree of integration between different markets during the nineties. Another interesting result is that the degree of integration between the Spanish and the American markets seems to be lower than that between the German and American markets in both periods considered.

Regarding the second approach -mean distances between sets of discount factors- Table 7 gives the main results when the benchmark is the American market and the number of assets in both sub-markets is equal to 10. Apart from the statistics reported in Table 5, Table 7 also reports the results of the mean distances between the set of discount factors in the American market and a fixed set made up of all vectors whose components range between 0.5 and 1.5, which are used as a yardstick.

It is interesting to note that the two most prominent features that appeared in Table 5 are also present here. That is, first, the mean of the distances is lower in the pair USA-USA than in any other pair irrespective of the period considered, and second, the distances between pairs of different countries are lower in 1995-99 than in 1990-95. Interestingly, in this case the mean of the integration measure within the American stock exchange remains almost unchanged during the nineties (it is only slightly higher during the second period). Also, the average of the mean distances between the fixed set and the set of discount factors for the American assets is slightly higher during the second period. 
Another interesting feature of the estimates resulting from the second approach is their low standard deviation compared with those obtained under the first approach. This possibly indicates that they are computed with a higher precision. Two different factors could explain the difference in precision: i) measures in the second approach are estimated with a larger data set, and ii) sample means are less sensitive to outliers than the sample minimum.

Table 8 shows the main results of the analysis when relative distances are considered and chart 5 plots the corresponding histograms. The results of this analysis are similar to those reported under the first approach. Firstly, empirical distributions of the relative distances shift to the left in the second period, suggesting an increase in the degree of integration between different markets during the second half of the decade. Conversely, the change in the distribution of the mean distance between the fixed set and the set of discount factors in the American market only changes slightly during the second period, the mean of the distribution being almost the same. Secondly, the degree of integration between the Spanish and the American markets seems to be lower than that between the German and American markets in each of the periods considered.

Finally, as a sort of robustness check, a parallel exercise is performed taking the Spanish market as the benchmark 27 . Also, as a by-product of this exercise we obtain estimations of the degree of integration between the German and the Spanish markets. The number of assets in sub-markets $A$ and $B$ is again 10 . The main results of this analysis appear in Tables 9 and 10 and Chart 6, which are, respectively, equivalent to Tables 7 and 8 and Chart 5. The results of this exercise are very similar to those obtained when the American market was the benchmark. In other words, the degree of integration between the Spanish market and the other two markets seems to increase during the second half of the decade. Interestingly, it is found that the integration between the German and the Spanish markets is, in both periods, higher than that between the Spanish and the American markets.

To sum up, the results of this section suggest that financial market integration between the domestic equity markets considered has increased during the nineties. This result seems to be robust as it holds for all the three possible pairs of markets and for both of the two measures of financial integration estimated.

\section{CONCLUSIONS AND POLICY IMPLICATIONS}

During the nineties, the linkages between national stock exchanges seem to have increased. Not only has the weight of foreign assets in agents' portfolios increased but so

\footnotetext{
27 Due to the small number of assets available in the data set of the German market -19 assets- we can not take it as benchmark.
} 
also have the correlation between stock indexes and the ability of each market return to explain the behaviour of returns on other markets. Nevertheless, it is worth noting that these indicators can not provide any information on the main driving forces behind these increasing linkages. In particular, as we have stressed in the paper, they can not be used to assess whether there has been a genuine increase in the degree of integration between national financial markets. This is an important shortcoming given that the welfare and policy implications of the apparent higher linkages differ according as to whether they are the consequence of greater market integration -i.e. less barriers of all kinds to free financial trade- or the consequence of, for example, a greater information globalisation in a world where barriers still remain.

Accordingly, we propose two refinements of a direct measure of financial market integration originally proposed by Chen and Knez (1995) and compute them for the American, German and Spanish stock exchanges in the nineties. Our analysis shows that during the nineties there has been an increase of the degree of integration among the markets considered.

This result has important implications when assessing the closer relationships observed between stock exchanges. Thus, for example, due to the entailed elimination of obstacles to free trade, greater financial market integration means higher financial market efficiency and an improvement in the risk-and-return combinations available to investors. This has to be viewed as a counter-argument to those who believe that markets are now too vulnerable to news due to their excessive links.

Greater market integration, on the other hand, reduces the ability of domestically focused policies to deal with the new problems arising in financial markets. It might be argued that the closer we are to a single world market, the greater the need for world-wide supervision, particularly if this greater integration is the result of solid structural trends, as seems to be the case. Whether such world-wide supervision should be provided by a single supervisor or by a very-closely-linked group of supervisors is, however, a different question. 


\section{REFERENCES}

Adler, and B. Dumas (1983): "International Portfolio Choice and Corporation Finance: A Synthesis“, Journal of Finance, 38, 925-984.

Black, F. (1976): "Studies in stock price volatility changes", Proceedings of the 1976 Business Meeting of the Business and Economics Statistics Section, American Statistical Association, 177-181.

Bollerslev, T. (1986): "Generalized autoregressive conditional heteroskedasticity", Journal of Econometrics, 31, 307-327.

Chen, Z. And P.J. Knez (1995): "Measurement of Market Integration and Arbitrage", Review of Financial Studies, 8 (2), 287-325.

Engle, R.F., T. Ito and W.L. Lin (1988): "Meteor showers or heat waves?: intra-daily volatility in the foreign exchange market", NBER Working Paper.

Engle, R.F. and V.K. Ng (1993): "Measuring and Testing the Impact of News on Volatility", Journal of Finance, 5, 1749-1778.

Glosten, L., R. Jagannathan and D. Runkle (1989): "Relationship between the expected value and the volatility of the nominal excess return on stocks", Working Paper, Department of Finance, Columbia University.

Hansen, L. P. and R. Jagannathan (1991): "Implications of Security Market Data for Models of Dynamic Economies", Journal of Political Economy, 99, 225-262.

Hansen, L. P. and R. Jagannathan (1997): "Assessing Specification Errors in Stochastic Discount Factor Models", The Journal of Finance, 52 (2), 557-590.

Le, S.V. (1991): "International investment diversification before and after the October 19, 1987 stock market crisis", Journal of Business Research, 22, 305-310.

Taylor, M.P. and I. Tonks (1989): "The Internationalisation of Stock Markets and the Abolition of UK Exchange Control", Review of Economics and Statistics, 71, 332-336. 


\section{ANNEX 1. DATA}

In Section 2, we use overall indexes for seven stock exchanges and sector indexes for the American exchange. The overall indexes are the following:

- S\&P 500 for New York 28 .

- FTSE all shares for London.

- $\quad$ CAC 40 for Paris.

- $\quad$ IGBM for Madrid.

- $\quad$ DAX 30 for Frankfurt.

- $\quad$ MIB all shares for Milan.

- NIKKEI 225 for Tokyo.

In all these indexes, stocks are weighted by their capitalisation and are calculated on a price-return basis -i.e. they only reflect capital gains. The source is the BIS, with the exception of the IGBM, where the source is the Banco de España.

The sector indexes for the American exchange are seven of the sector indexes of the S\&P 500. They are the following:

- $\quad X F$ : financial sector.

- TECS: technology sector.

- HLTS: health care sector.

- CPGS: capital good sector.

- ENRS: energy sector.

- XU: utility sector.

- XT: transportation sector.

28 In fact, the S\&P 500 index also includes stocks quoted in other exchanges such NASDAQ and AMEX. However, the number of assets quoted on the NYSE represents more than $90 \%$ of the total. 
This data set is taken from Bloomberg.

In Section 3, we use information on prices and payoffs for a sample of (portfolios of) assets in each of three different markets -New York, Frankfurt and Madrid. The payoffs are indexes calculated on a total-return basis representing the performance of portfolios of assets, and prices are the same series but lagged one period. For the Frankfurt market we take the 19 CDAX sector indexes. These indexes are calculated by the Deutsche Börse with the gross dividends reinvested in the index and with correction for capital increases. For the NYSE we construct total-return indexes for 80 of the industry indexes of the S\&P 500 . The computation is performed reinvesting gross dividends into those industry indexes. More formally, we use the following expression:

$T R I_{t}=\prod_{i=0}^{t}\left(1+\frac{d_{i}}{I_{i}}\right) I_{t}$

where $\mathrm{TRI}_{\mathrm{t}}$ stands for total return index in period $t, d_{i}$ is the sum of all gross dividends expressed in index points- paid in period $i$ by stocks belonging to the index and $I_{j}$ for $j=i, t$, is the price index in period $\mathrm{j}$. The information needed to construct the previous data set was taken from Bloomberg.

Finally, for the Madrid exchange, we construct 43 indexes representing the total return on 43 of the stocks which have been listed throughout the period studied. The total return is computed applying the previous expression, when the price index has been corrected for capital increases. The latter index is calculated after eliminating the impact of the correction for dividends made by the Bolsa de Madrid $^{29}$ in their individual price indexes. The source of the data we use to compute these indexes is the Banco de España for individual indexes and the Bolsa de Madrid for dividends.

\footnotetext{
${ }^{29}$ Bolsa de Madrid calculates individual price indexes for those stocks belonging to the global index IGBM. These indexes are corrected for dividends in such a way that the drop in price on the ex-dividend day is eliminated, but as they are not reinvested into the index this correction was not useful for our purpose. That is why we have eliminated the impact of this correction.
} 
Table 1. Correlation between stock indexes. Weekly data.

\begin{tabular}{|c|c|c|c|c|c|c|c|c|c|c|c|c|}
\hline \multicolumn{13}{|c|}{ a) Between national stock exchanges (a) } \\
\hline & \multicolumn{2}{|c|}{ USA } & \multicolumn{2}{|c|}{ UK } & \multicolumn{2}{|c|}{ FRANCE } & \multicolumn{2}{|c|}{ SPAIN } & \multicolumn{2}{|c|}{ GERMANY } & \multicolumn{2}{|c|}{ ITALY } \\
\hline & $1990-4$ & $1995-9(b)$ & $1990-4$ & $1995-9(b)$ & $1990-4$ & $1995-9(b)$ & $1990-4$ & $1995-9(b)$ & $1990-4$ & $1995-9(b)$ & $1990-4$ & $1995-9(b)$ \\
\hline UK & 0.42 & 0.61 & & & & & & & & & & \\
\hline FRANCE & 0.39 & 0.60 & 0.58 & 0.70 & & & & & & & & \\
\hline SPAIN & 0.40 & 0.59 & 0.51 & 0.70 & 0.58 & 0.74 & & & & & & \\
\hline GERMANY & 0.29 & 0.58 & 0.53 & 0.70 & 0.62 & 0.74 & 0.52 & 0.74 & & & & \\
\hline ITALY & 0.20 & 0.45 & 0.38 & 0.53 & 0.42 & 0.62 & 0.45 & 0.67 & 0.47 & 0.60 & & \\
\hline JAPAN & 0.34 & 0.33 & 0.37 & 0.32 & 0.34 & 0.32 & 0.46 & 0.30 & 0.31 & 0.28 & 0.24 & 0.23 \\
\hline \multicolumn{13}{|c|}{ b) Between sectors within the US stock exchange (a) } \\
\hline & \multicolumn{2}{|c|}{ TECS } & \multicolumn{2}{|c|}{$\mathrm{XF}$} & \multicolumn{2}{|c|}{ HLTS } & \multicolumn{2}{|c|}{ CPGS } & \multicolumn{2}{|c|}{ ENRS } & \multicolumn{2}{|c|}{$\mathrm{XU}$} \\
\hline & $1990-4$ & $1995-9(b)$ & $1990-4$ & $1995-9(b)$ & $1990-4$ & $1995-9(b)$ & $1990-4$ & $1995-9(b)$ & $1990-4$ & $1995-9(b)$ & $1990-4$ & $1995-9(b)$ \\
\hline $\mathrm{XF}$ & 0.63 & 0.55 & & & & & & & & & & \\
\hline HLTS & 0.43 & 0.53 & 0.42 & 0.67 & & & & & & & & \\
\hline CPGS & 0.84 & 0.69 & 0.73 & 0.75 & 0.48 & 0.60 & & & & & & \\
\hline ENRS & 0.29 & 0.25 & 0.39 & 0.45 & 0.29 & 0.32 & 0.47 & 0.47 & & & & \\
\hline XU & 0.28 & 0.08 & 0.46 & 0.46 & 0.29 & 0.36 & 0.37 & 0.31 & 0.46 & 0.40 & & \\
\hline XT & 0.62 & 0.45 & 0.66 & 0.68 & 0.38 & 0.45 & 0.78 & 0.71 & 0.39 & 0.42 & 0.34 & 0.34 \\
\hline
\end{tabular}

(a) See Annex 1 for a description of national and sectoral indexes.

(b) Up to June. 
Table 2. The explanatory power of other-market returns on the own-market return. Daily data.

\begin{tabular}{|c|c|c|c|c|c|c|c|c|}
\hline \multirow{7}{*}{$1990-4$} & \multirow{7}{*}{$\begin{array}{l}\text { SSR univ (1) } \\
\text { SSR VAR (2) } \\
((1)-(2)) /(1) \\
\text { N. Obs. } \\
\text { q (b) }\end{array}$} & \multicolumn{7}{|c|}{ a) National stock indexes (a) } \\
\hline & & JAP & UK & GERMANY & FRANCE & ITALY & SPAIN & USA \\
\hline & & 3020.51 & 855.27 & 1680.48 & 1747.09 & 1868.50 & 1455.96 & 732.30 \\
\hline & & 2840.19 & 779.88 & 1480.46 & 1625.46 & 1730.57 & 1366.6 & 719.86 \\
\hline & & $5.97 \%$ & $8.81 \%$ & $11.90 \%$ & $6.96 \%$ & $7.38 \%$ & $6.14 \%$ & $1.70 \%$ \\
\hline & & & & & 1299 & & & \\
\hline & & & & & 12 & & & \\
\hline \multirow{5}{*}{$1995-9$ (c) } & SSR univ (1) & 2404.09 & 736.37 & 2001.04 & 1798.24 & 2071.64 & 1631.9 & 1093.83 \\
\hline & SSR VAR (2) & 2174.19 & 624.65 & 1494.08 & 1611.14 & 1519.17 & 1480.8 & 1073.12 \\
\hline & $((1)-(2)) /(1)$ & $9.56 \%$ & $15.17 \%$ & $25.33 \%$ & $10.40 \%$ & $26.67 \%$ & $9.26 \%$ & $1.89 \%$ \\
\hline & N. Obs. & \multicolumn{7}{|c|}{1150} \\
\hline & $q(b)$ & \multicolumn{7}{|c|}{6} \\
\hline \multirow{7}{*}{$1990-4$} & & \multicolumn{7}{|c|}{ b) Sectoral indexes (a) } \\
\hline & & TECS & $\mathrm{XF}$ & HLTS & CPGS & ENRS & $X U$ & XT \\
\hline & SSR univ (1) & 1330.51 & 1404.80 & 1614.32 & 929.67 & 982.95 & 902.14 & 1431.88 \\
\hline & SSR VAR (2) & 1315.97 & 1387.38 & 1597.42 & 916.96 & 973.79 & 894.95 & 1397.45 \\
\hline & $((1)-(2)) /(1)$ & $1.09 \%$ & $1.24 \%$ & $1.05 \%$ & $1.37 \%$ & $0.93 \%$ & $0.80 \%$ & $2.40 \%$ \\
\hline & N. Obs. & \multicolumn{7}{|c|}{1299} \\
\hline & $q(b)$ & \multicolumn{7}{|c|}{6} \\
\hline \multirow{5}{*}{$1995-9$ (c) } & SSR univ (1) & 3133.84 & 2066.84 & 1804.60 & 1306.17 & 1705.21 & 688.91 & 1556.00 \\
\hline & SSR VAR (2) & 3102.66 & 2056.92 & 1780.77 & 1284.77 & 1681.02 & 655.91 & 1530.38 \\
\hline & $((1)-(2)) /(1)$ & $0.99 \%$ & $0.48 \%$ & $1.32 \%$ & $1.64 \%$ & $1.42 \%$ & $4.79 \%$ & $1.65 \%$ \\
\hline & N. Obs. & \multicolumn{7}{|c|}{1150} \\
\hline & $q(b)$ & \multicolumn{7}{|c|}{6} \\
\hline
\end{tabular}

(a) See Annex 1 for a description of national and sectoral stock indexes

(b) $q$ is the number of new regressors in the VAR with respect to the univariate model.

(c) Up to June. 
Table 3. The explanatory power of other-market returns. Daily data without outliers (a).

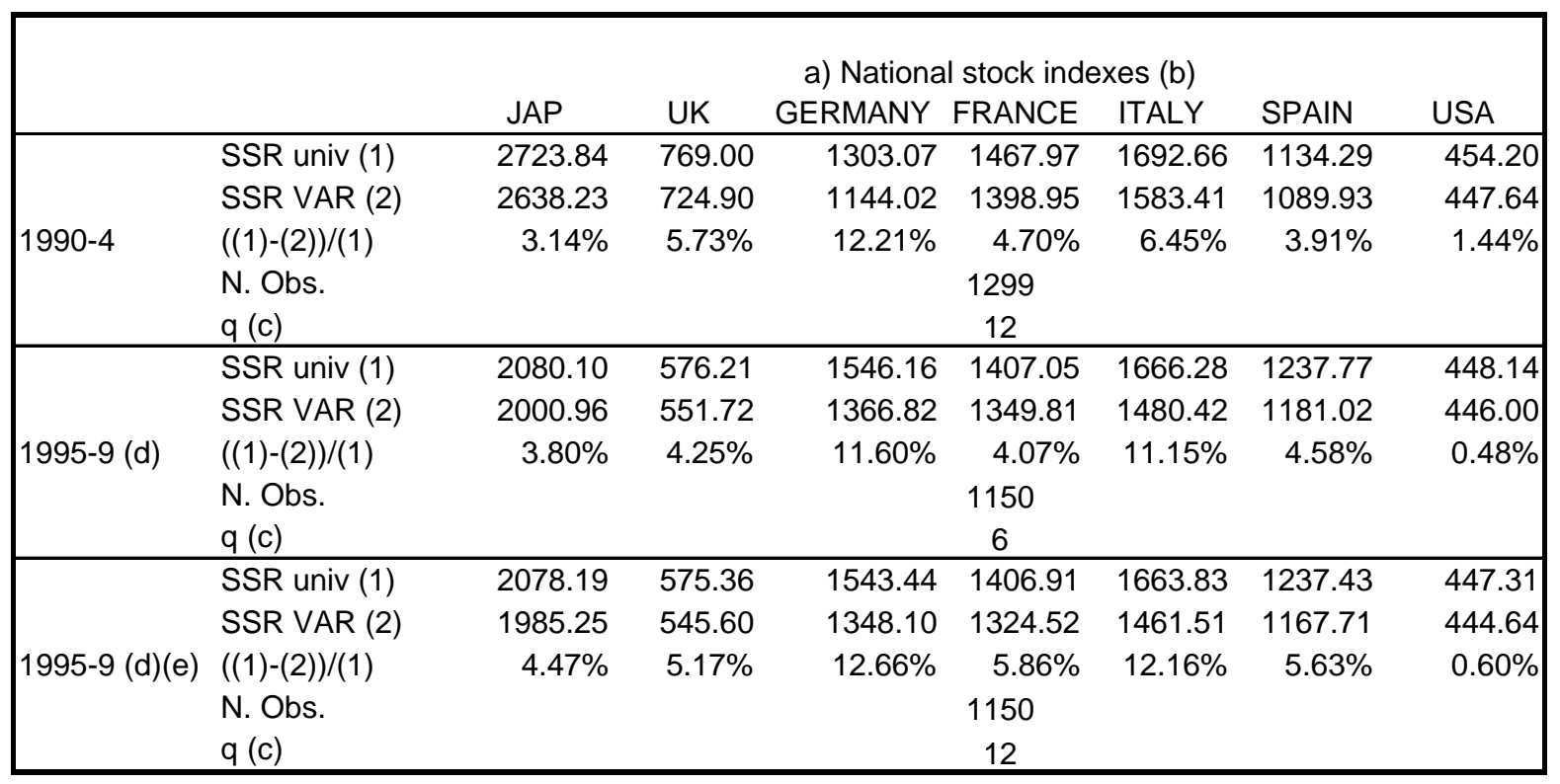

(a) Returns 2 standard deviations away from its average have been intervened as commented in the main text.

(b) See Annex 1 for a description of national and sectoral stock indexes.

(c) $q$ is the number of new regressors in the VAR model when compared with the univariate model.

(d) Up to June.

(e) The VAR model has been over-parameterised by including an additional lag. 
Table 4. Gosten-Jagannathan-Runkle conditional variance models.

\begin{tabular}{|c|c|c|c|c|c|c|c|c|c|c|c|c|}
\hline \multirow[b]{2}{*}{$a_{0}(\mathrm{se})$} & JAPAN (a) & \multicolumn{2}{|c|}{ UK } & \multicolumn{2}{|c|}{ GERMANY } & \multicolumn{2}{|c|}{ FRANCE } & \multicolumn{2}{|c|}{ ITALY } & \multicolumn{2}{|c|}{ SPAIN } & USA \\
\hline & $0.03 \quad(.01)$ & 0.32 & $(.01)$ & 0.01 & $(.00)$ & 0.08 & $(.02)$ & 0.07 & $(.01)$ & 0.06 & $(.01)$ & $0.01 \quad(.00)$ \\
\hline$a_{1}(s e)$ & $0.02 \quad(.001)$ & 0.15 & $(.02)$ & 0.02 & $(.00)$ & -- & & 0.05 & $(.01)$ & -- & & $0.02 \quad(.01)$ \\
\hline $\mathrm{a}_{2}(\mathrm{se})$ & -- & 0.12 & $(.02)$ & - & & - & & - & & - & & -- \\
\hline$b_{1}(s e)$ & $0.9 \quad(.01)$ & -- & & 0.94 & (.01) & 0.84 & $(.02)$ & 0.85 & & 0.81 & (.02) & $0.90 \quad(.01)$ \\
\hline$g_{1}(s e)$ & $0.12 \quad(.01)$ & - & & 0.04 & $(.01)$ & 0.08 & $(.01)$ & 0.04 & (.02) & 0.07 & $(.02)$ & $0.08 \quad(.01)$ \\
\hline$d_{1, J A P}$ & -- & 0.008 & $(.004)$ & -- & & 0.007 & $(.003)$ & - & & 0.007 & $(.003)$ & -- \\
\hline $\mathrm{dd}_{1, \mathrm{JAP}}$ & - & -- & & - & & - & & - & & - & & - \\
\hline$d_{1, U K}$ & -- & - & & - & & -- & & -- & & -- & & -- \\
\hline $\mathrm{dd}_{1, \mathrm{UK}}$ & -- & -- & & -- & & -- & & -- & & - & & $0.02 \quad(.01)$ \\
\hline$d_{1, G E R}$ & -- & - & & -- & & - & & - & & - & & -- \\
\hline $\mathrm{dd}_{1, \mathrm{G} \in \mathrm{R}}$ & $0.013(.006)$ & 0.06 & $(.01)$ & -- & & 0.02 & $(.01)$ & -- & & 0.08 & $(.01)$ & -- \\
\hline$d_{1, \text { RRA }}$ & -- & 0.06 & $(.01)$ & -- & & -- & & -- & & 0.03 & $(.01)$ & - \\
\hline $\mathrm{dd}_{1, \mathrm{RRA}}$ & - & -0.06 & $(.01)$ & -- & & -- & & - & & -0.03 & $(.01)$ & -- \\
\hline$d_{1, T A}$ & -- & - & & -- & & -- & & - & & 0.02 & $(.01)$ & -- \\
\hline $\mathrm{dd}_{1, \mathrm{TA}}$ & $0.008(.003)$ & - & & -- & & -- & & - & & -0.02 & $(.01)$ & -- \\
\hline$d_{1, S P A}$ & -- & -- & & -- & & 0.03 & $(.01)$ & 0.03 & $(.01)$ & - & & $0.007(.002)$ \\
\hline $\mathrm{dd}_{1, \mathrm{SPA}}$ & - & - & & - & & - & & -- & & - & & - \\
\hline$d_{1, U S A}$ & -- & -- & & 0.03 & $(.01)$ & -- & & - & & - & & - \\
\hline $\mathrm{dd}_{1, \mathrm{USA}}$ & -- & -- & & -0.02 & $(.01)$ & -- & & -- & & - & & -- \\
\hline $\mathrm{CH} 1$ (b) & 0.21 & 1.5 & 54 & 0.8 & & 0.0 & 02 & 0.9 & & 0.2 & & 1.17 \\
\hline $\mathrm{CH} 5$ & 0.78 & 3.4 & 47 & 1.4 & & 9.6 & 64 & 1.6 & & 0.6 & & 1.68 \\
\hline $\mathrm{T} 1$ (c) & -0.09 & -0.8 & 84 & 1.7 & & -1.8 & 80 & -0. & & 2.4 & & 0.01 \\
\hline $\mathrm{T} 2$ & -0.54 & -0. & 35 & 0.6 & & -1. & 12 & 0.8 & & 1.6 & & -0.78 \\
\hline T3 & -0.10 & 0.6 & 65 & -0.4 & & -0 . & 10 & -1.3 & 33 & -1.8 & & 0.03 \\
\hline Nobs & 2452 & 24 & 52 & 245 & & 24 & 52 & 245 & 52 & 245 & & 2452 \\
\hline
\end{tabular}

(a) See Annex 1 for a description of national and sectoral stock indexes

(b) $\mathrm{CH} 1$ and $\mathrm{CH} 5$ are, respectively, tests for residual conditional variance up to orders 1and 5 . Under the null (no residual variance) their distribution is chi-squared with 1 and 5 degrees of freedom

(c) T1, T2 and T3 are, respectively, the sign, positive bias and negative bias tests in Engle and $\mathrm{Ng}$ (1993).

Under the null (no residual asymmetry and no positive or negative non-linearity) they display a Student-t distribution. 
Table 5: Minimum distances between sets of stochastic discount factors, benchmark USA (a)

\begin{tabular}{|lrrrrrr|}
\hline & & $1990-1994$ & & \multicolumn{4}{c|}{$1995-1999$} \\
Mean & USA-USA & USA-GER & USA-SPA & USA-USA & USA-GER & USA-SPA \\
\cline { 2 - 7 } Minimum & 111.7 & 160.5 & 180.8 & 88.6 & 92.0 & 111.7 \\
Maximum & 75.0 & 76.1 & 108.9 & 60.2 & 48.0 & 75.3 \\
Standard deviation & 173.5 & 252.5 & 279.2 & 152.7 & 172.5 & 231.7 \\
Average no of iterations & 21.3 & 35.6 & 32.0 & 18.0 & 24.9 & 27.2 \\
\hline
\end{tabular}

(a) Minimum distances expressed in basis points.

This table shows, for each period and pair of markets, some summary statistics of 100 averages of the estimations of the minimum distances between the sets of discount factors in sub-markets $A$ and $B$.

Each average is computed for a fixed set DA and 100 differents sets DB. DA and DB are, respectively, the sets of admissible discount factors in sub-markets $A$ and $B$, and are defined as the discount factors that price stocks belonging to sub-markets $A$ and $B$. Submarket $A$ is a sample of 44 stocks quoted in the benchmark market and sub-market $B$ is a sample of 10 stocks quoted in the other market of the pair.

Table 6: Relative minimum distances between sets of stochastic discount factors, benchmark USA (a)

\begin{tabular}{|lrrrr|}
\hline & USA-GER & \multicolumn{3}{c|}{ USA-SPA } \\
\cline { 2 - 5 } Mean & $90-94$ & $95-99$ & $90-94$ & $95-99$ \\
\cline { 2 - 5 } Minimum & 48.8 & 3.4 & 69.1 & 23.2 \\
Maximum & -13.6 & -32.8 & 9.2 & -28.2 \\
Standard deviation & 130.4 & 66.1 & 152.6 & 86.1 \\
\% positive & 33.4 & 19.2 & 28.4 & 22.3 \\
\hline
\end{tabular}

(a) Minimum distances expressed in basis points.

This table shows, for each period and pair of markets, some summary statistics of the 100 averages of estimations of the relative minimum distances between the sets of discount factors in sub-markets A and B. For the pair USA-GER, the relative distance is calculated as the difference between averages of minimum distances when sub-markets $A$ and $B$ are made up, respectively, of stocks belonging to the American and German markets and averages of minimum distances when both sub-markets are made up of stocks belonging to the American market. Sub-market $A$ is a sample of 44 stocks quoted on the benchmark market and sub-market $B$ is a sample of 10 stocks quoted in the other market of the pair. 
Table 7: Mean distances between sets of stochastic discount factors, benchmark USA (a)

\begin{tabular}{|lrrrrrrrr|}
\hline & \multicolumn{3}{c|}{$1990-1994$} & & \multicolumn{5}{c|}{$1995-1999$} \\
Mean & USA-USA USA-GER USA-SPA USA-FIX & USA-USA & USA-GEF USA-SPA & USA-FIX \\
\cline { 2 - 8 } Minimum & 432.9 & 444.9 & 452.0 & 639.3 & 434.2 & 441.2 & 443.0 & 640.4 \\
Maximum & 403.2 & 413.0 & 424.3 & 609.6 & 404.7 & 402.4 & 410.1 & 606.8 \\
Standard deviation & 479.6 & 497.9 & 489.0 & 687.7 & 470.8 & 481.0 & 486.4 & 681.3 \\
Average no of iterations & 15.2 & 18.8 & 13.7 & 15.6 & 15.0 & 17.4 & 15.5 & 16.4 \\
\hline
\end{tabular}

(a) Mean distances expressed in basis points.

This table shows, for each period and pair of markets, some summary statistics of 100 averages of the estimations of the mean distances between the sets of discount factors in sub-markets $A$ and $B$.

Averages of mean distances are computed for a fixed set DA and 100 differents sets DB. DA and DB are, respectively, the sets of admissible discount factors in sub-markets $A$ and $B$, and are defined as the discount factors that price stocks belonging to sub-markets $A$ and $B$. Sub-market $A$ is a sample of 10 stocks quoted in the benchmark market and submarket $B$ is a sample of 10 stocks quoted in the other market of the pair.

In the pair USA-FIX, DB is the set formed by all vectors whose components range between 0.5 and 1.5. This distance is used as a yardstick.

Table 8: Relative mean distances between sets of stochastic discount factors, benchmark USA (a)

\begin{tabular}{|lrrrrrr|}
\hline & \multicolumn{2}{c}{ USA-GER } & \multicolumn{2}{c|}{ USA-SPA } & \multicolumn{2}{c|}{ USA-FIX } \\
& $90-94$ & $95-99$ & $90-94$ & $95-99$ & $90-94$ & $95-99$ \\
\cline { 2 - 7 } Mean & 12.0 & 7.0 & 19.1 & 8.8 & 206.4 & 206.2 \\
Minimum & -9.2 & -21.9 & 0.7 & -3.3 & 177.9 & 169.9 \\
Maximum & 39.2 & 30.2 & 37.3 & 24.1 & 238.0 & 232.4 \\
Standard deviation & 9.0 & 9.5 & 8.3 & 5.7 & 11.9 & 10.5 \\
\% positive & 90.0 & 79.0 & 100.0 & 95.0 & 100.0 & 100.0 \\
\hline
\end{tabular}

(a) Mean distances expressed in basis points.

This table shows, for each period and pair of markets, some summary statistics of the 100 averages of estimations of the relative mean distances between the sets of discount factors in sub-markets $A$ and B. For the pair USA-GER, the relative distance is calculated as the difference between averages of mean distances when sub-markets $A$ and $B$ are made up of stocks belonging, respectively, to the American and German markets and averages of mean distances when both sub-markets are made up of stocks belonging to the American market. Each average is computed with a fixed sub-market $A$, made up of 10 American stocks, and 100 different sets DB. Sub-market $B$ is sample of 10 stocks quoted in one of the three studied markets. For the pair USA-FIX the relative mean difference is calculated as the difference between the mean distance between sub-market $A$ and the fixed set and the average of the mean distances when both sub-markets are made up of stocks belonging to the American market. 
Table 9: Mean distances between sets of stochastic discount factors, benchmark SPA (a)

\begin{tabular}{|lrrrrrrrr|}
\hline & \multicolumn{3}{c}{$1990-1994$} & & \multicolumn{5}{c|}{$1995-1999$} \\
Mean & SPA-SPA SPA-GER SPA-USA SPA-FIX & SPA-SPA & SPA-GER SPA-USA & SPA-FIX \\
\cline { 2 - 9 } Minimum & 449.9 & 460.6 & 467.3 & 655.2 & 434.0 & 439.1 & 441.4 & 639.3 \\
Maximum & 422.5 & 420.8 & 425.4 & 621.3 & 399.2 & 407.3 & 411.6 & 615.9 \\
Standard deviation & 502.2 & 518.6 & 529.6 & 698.7 & 476.1 & 476.8 & 478.2 & 677.1 \\
Average no of iterations & 14.5 & 19.5 & 20.3 & 16.3 & 16.3 & 16.3 & 14.3 & 12.4 \\
\hline
\end{tabular}

(a) Mean distances expressed in basis points.

This table shows, for each period and pair of markets, some summary statistics of 100 averages of the estimations of the mean distances between the sets of discount factors in sub-markets $A$ and $B$.

Averages of mean distances are computed for a fixed set DA and 100 differents sets DB. DA and DB are, respectively, the sets of admissible discount factors in sub-markets $A$ and $B$, and are defined as the discount factors that price stocks belonging to sub-markets $A$ and $B$. Sub-market $A$ is a sample of 10 stocks quoted in the benchmark market and submarket $B$ is a sample of 10 stocks quoted in the other market of the pair.

In the pair SPA-FIX, DB is the set formed by all vectors whose components range between 0.5 and 1.5 . This distance is used as a yardstick.

Table 10: Relative mean distances between sets of stochastic discount factors, benchmark SPA (a)

\begin{tabular}{|lrrrrrr|}
\hline & \multicolumn{2}{c}{ SPA-GER } & \multicolumn{2}{c|}{ SPA-USA } & \multicolumn{2}{c|}{ SPA-FIX } \\
& $90-94$ & $95-99$ & $90-94$ & $95-99$ & $90-94$ & $95-99$ \\
\cline { 2 - 7 } Mean & 10.7 & 5.0 & 17.4 & 7.4 & 205.4 & 205.2 \\
Minimum & -24.0 & -10.7 & -24.9 & -17.4 & 175.6 & 175.6 \\
Maximum & 38.4 & 25.2 & 49.5 & 19.5 & 232.9 & 234.7 \\
Standard deviation & 12.4 & 8.6 & 13.0 & 7.0 & 12.2 & 10.6 \\
$\%$ positive & 84.0 & 74.0 & 88.0 & 85.0 & 100.0 & 100.0 \\
\hline
\end{tabular}

(a) Mean distances expressed in basis points.

This table shows, for each period and pair of markets, some summary statistics of the 100 averages of estimations of the relative mean distances between the sets of discount factors in sub-markets A and B. For the pair SPA-GER, the relative distance is calculated as the difference between averages of mean distances when sub-markets $A$ and $B$ are made up of stocks belonging, respectively, to the Spanish and German markets and averages of mean distances when both sub-markets are made up of stocks belonging to the Spanish market. Each average is computed with a fixed sub-market $A$, consisting of 10 Spanish stocks, and 100 different sets DB. Sub-market $B$ is a sample of 10 stocks quoted in one of the three studied markets.

For the pair SPA-FIX the relative mean difference is calculated as the difference between the mean distance between sub-market $A$ and the fixed set and the average of the mean distances when both sub-markets are made up of stocks belonging to the Spanish market. 
Chart 1. Direct and portfolio investment abroad as a percentage of GDP.

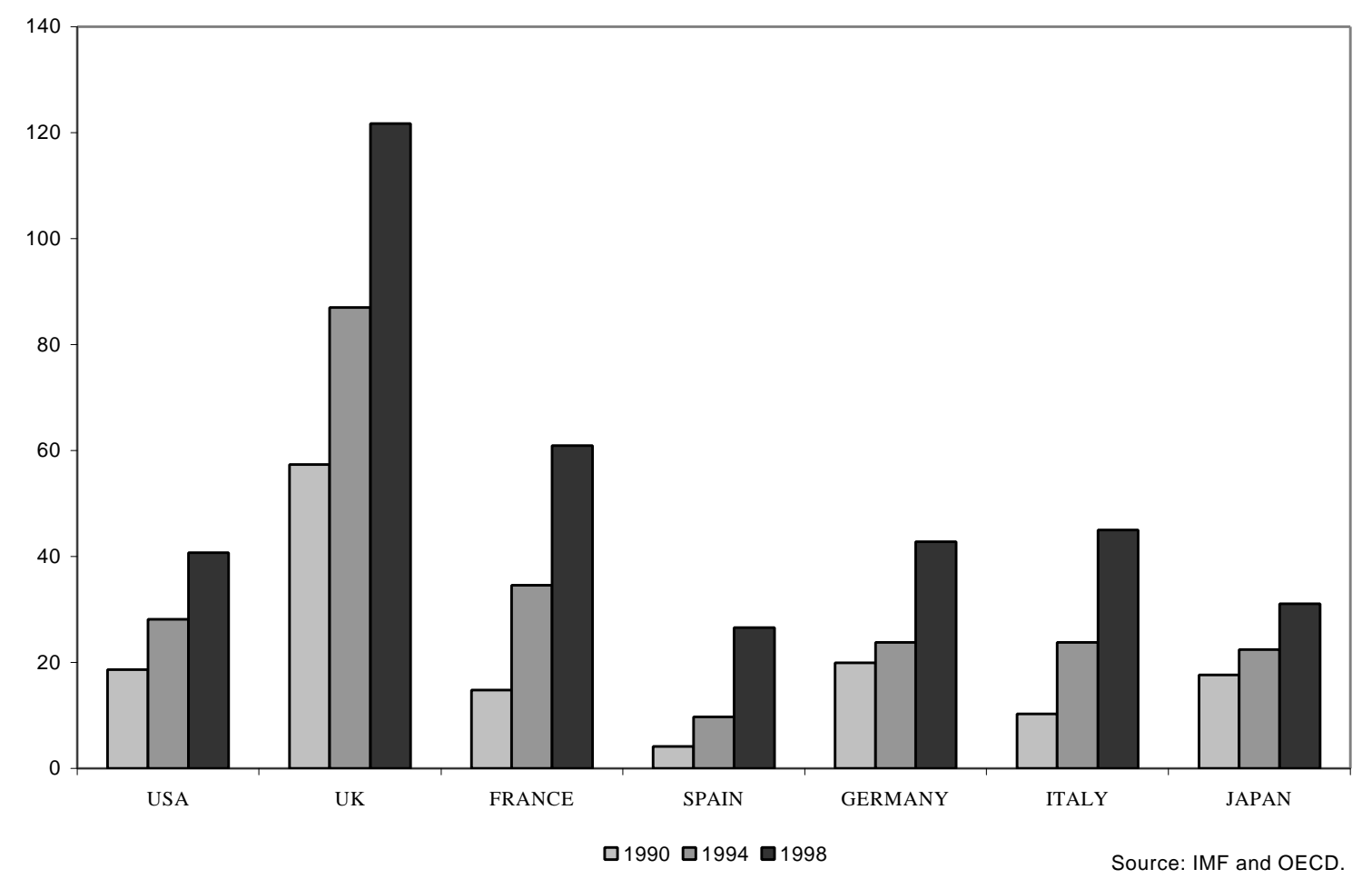


Chart 2. Mean distance between sets of admissible discount factors as a measure of integration.

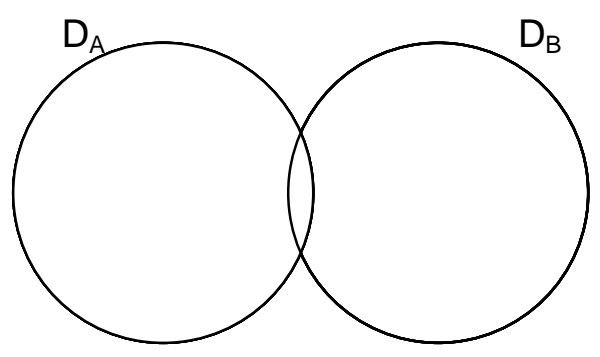

Low degree of integration

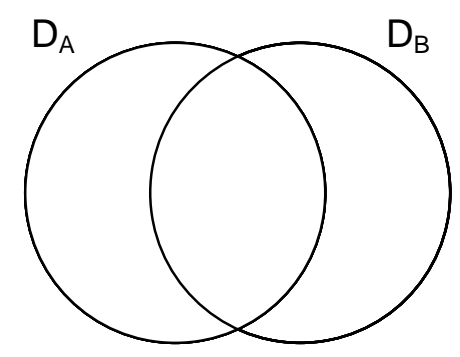

High degree of integration 
Chart 3. Illustration of algorithm 1.

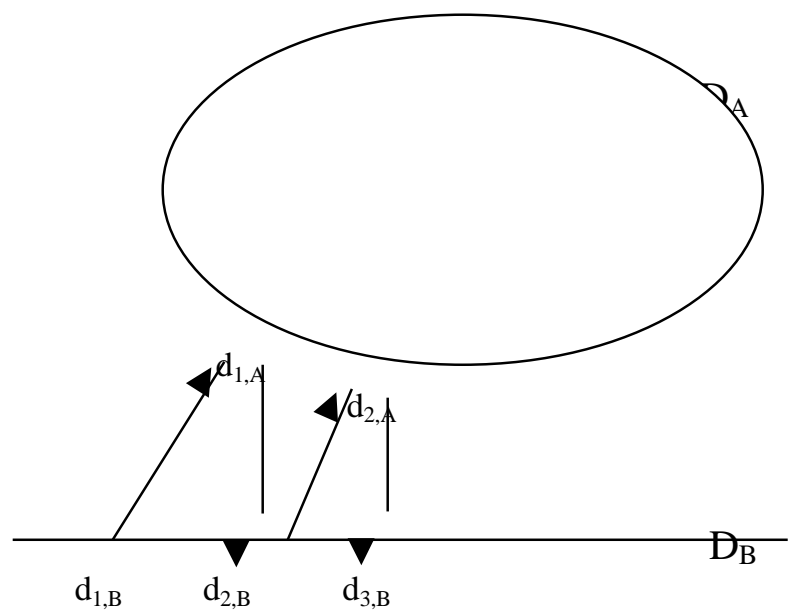

$D_{A}$ and $D_{B}$ are, respectively, the set of stochastic discount factors for sub-markets $A$ and $B$. $d_{1, B}$ is the point in $D_{B}$ used in the first iteration and $d_{1, A}$ is their least square projection onto $D_{A}$. Similarly, $d_{2, B}$ is the least square projection of $d_{1, A}$ onto $D_{B}, d_{2, A}$ is the least square projection of $d_{2, B}$ onto $D_{A}$, and $d_{3, B}$ is the least square projection of $d_{2, A}$ onto $D_{B}$. 
Chart 4.- Distribution of the relative minimum distances between sets of stochastic discount factors, benchmark USA
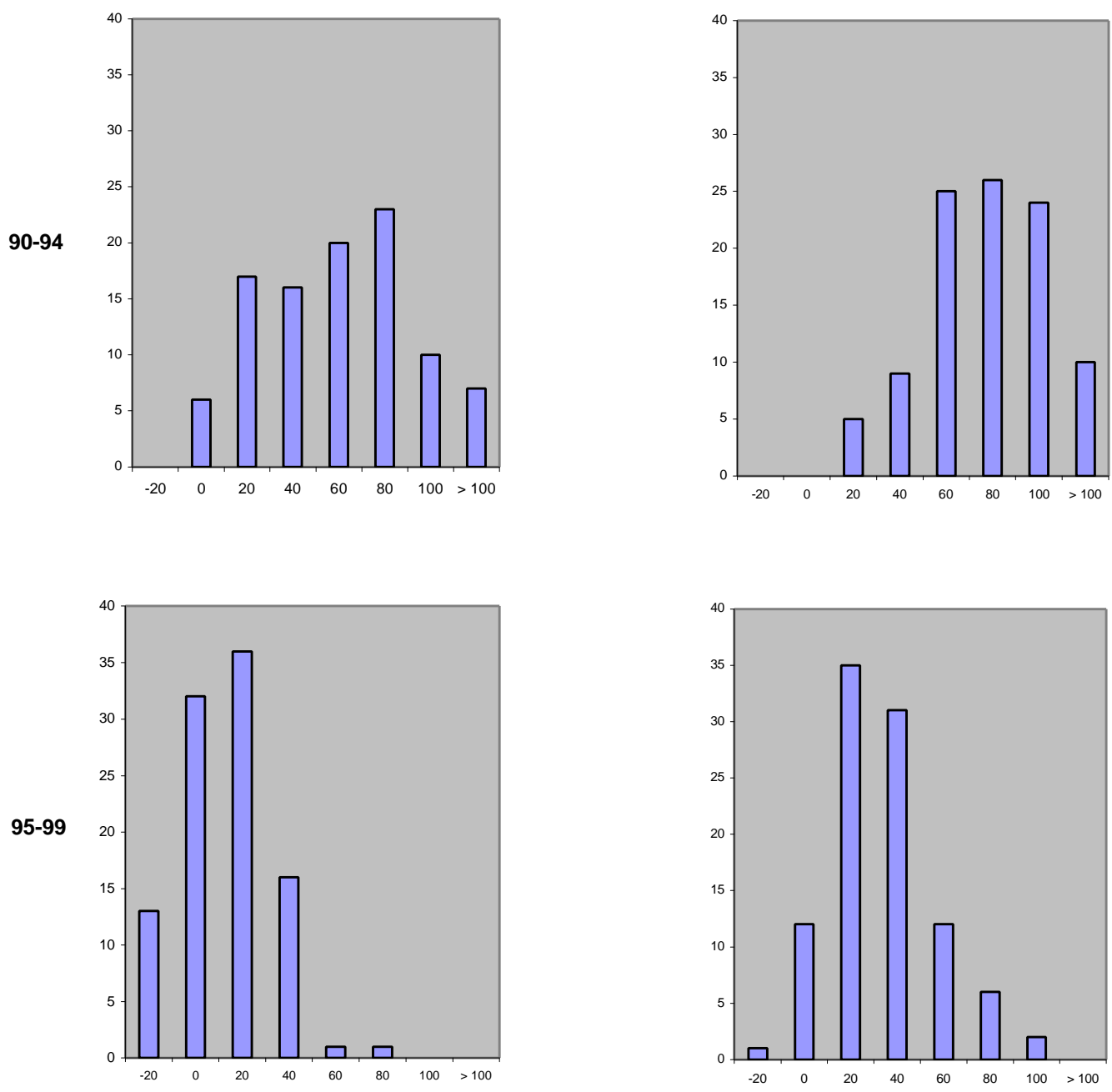

USA-GER

USA-SPA

(a) Minimum distances expressed in basis points.

See notes of table 6. 
Chart 5.- Distribution of the relative mean distances between sets of stochastic discount factors, benchmark USA
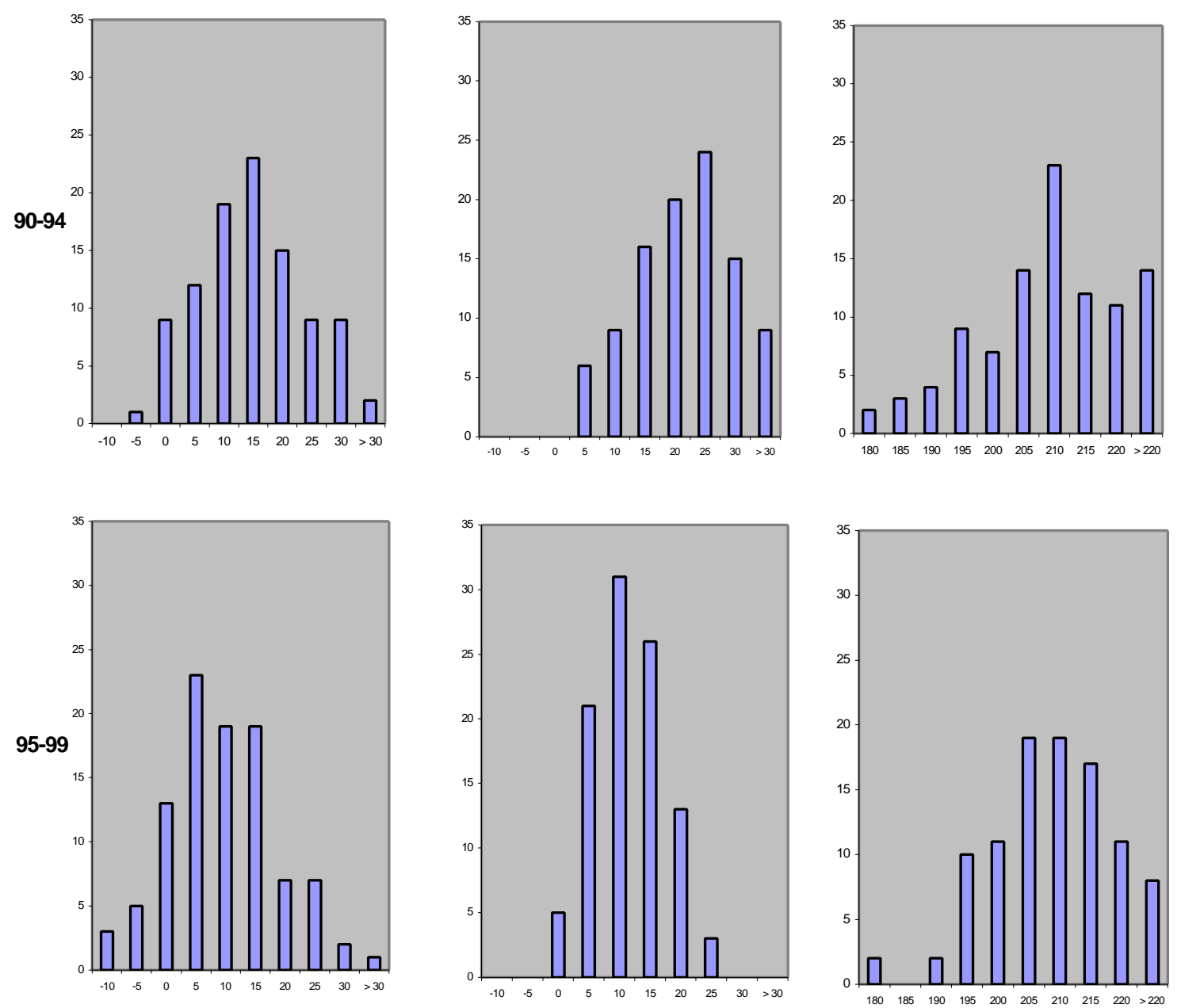

USA-GER

USA-SPA

USA-FIX

(a) Mean distances expressed in basis points.

See notes of table 8 . 
Chart 6.- Distribution of the relative mean distances between sets of stochastic discount factors, benchmark SPA (a)
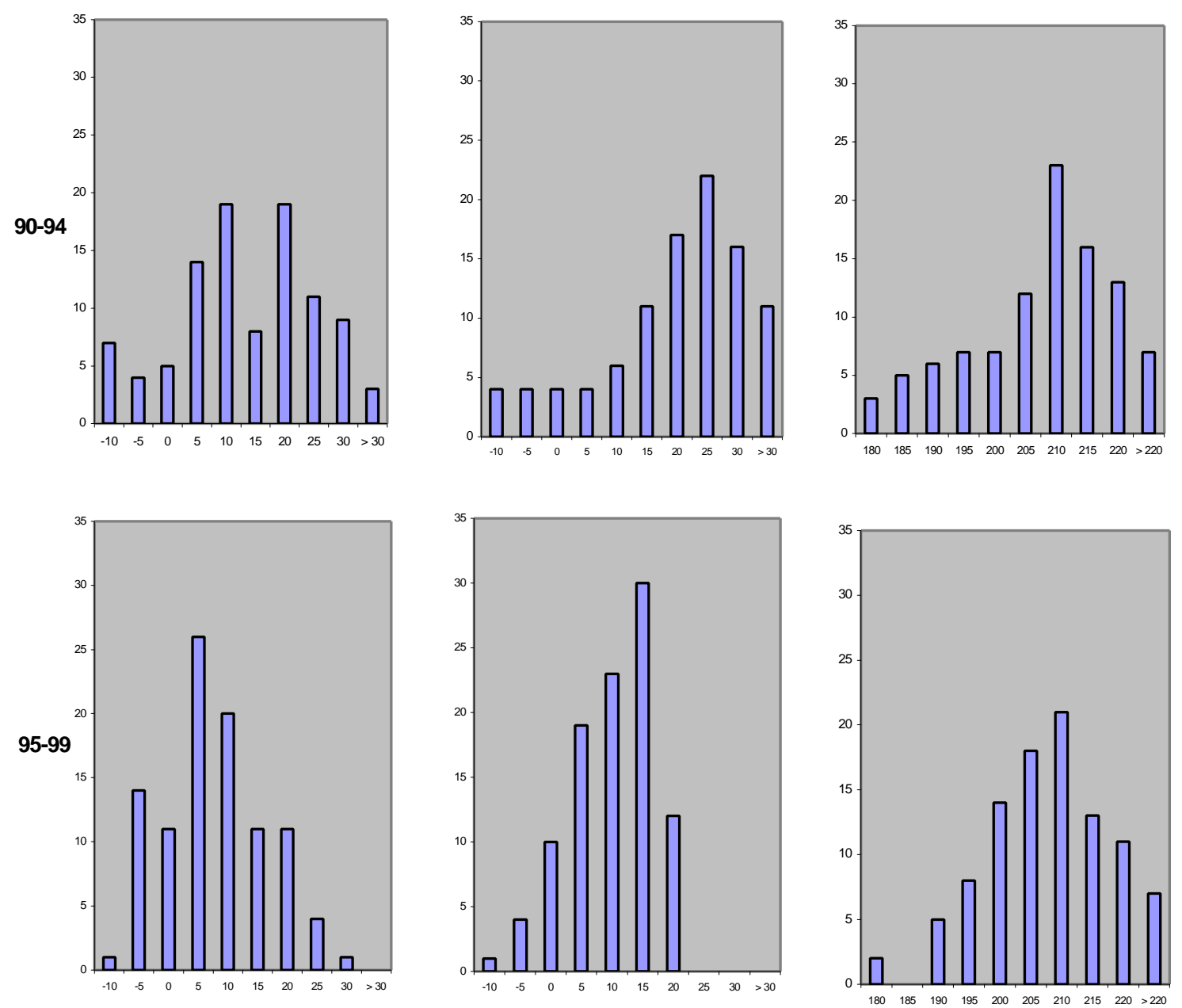

SPA-GER

SPA-USA

SPA-FIX

(a) Mean distances expressed in basis points.

See notes of table 10. 